University of Nebraska - Lincoln

DigitalCommons@University of Nebraska - Lincoln

2002

\title{
Life History and Laboratory Rearing of Pseudometapterus umbrosus (Heteroptera: Reduviidae) with Descriptions of Immatures Stages
}

Jeffrey Bradshaw

University of Nebraska-Lincoln, jbradshaw2@unl.edu

J. E. McPherson

Southern Illinois University, mcpherson@zoology.siu.edu

Follow this and additional works at: https://digitalcommons.unl.edu/panhandleresext

Part of the Agriculture Commons

Bradshaw, Jeffrey and McPherson, J. E., "Life History and Laboratory Rearing of Pseudometapterus umbrosus (Heteroptera: Reduviidae) with Descriptions of Immatures Stages" (2002). Panhandle Research and Extension Center. 36.

https://digitalcommons.unl.edu/panhandleresext/36

This Article is brought to you for free and open access by the Agricultural Research Division of IANR at DigitalCommons@University of Nebraska - Lincoln. It has been accepted for inclusion in Panhandle Research and Extension Center by an authorized administrator of DigitalCommons@University of Nebraska - Lincoln. 


\title{
Life History and Laboratory Rearing of Pseudometapterus umbrosus (Heteroptera: Reduviidae) with Descriptions of Immatures Stages
}

\author{
J. D. BRADSHAW ${ }^{1}$ AND J. E. MCPHERSON \\ Department of Zoology, Southern Illinois University at Carbondale, Carbondale, IL 62901
}

Ann. Entomol. Soc. Am. 95(2): 192-200 (2002)

\begin{abstract}
The life history of the emesine reduviid Pseudometapterus umbrosus (Blatchley) was studied in southern Illinois from February 1999 to November 2000, and the immature stages were described. The bug also was reared from egg to adult under controlled laboratory conditions. This univoltine species occurred on the rock faces of sandstone bluffs often in association with plants and spider webs. Adults and nymphs preyed primarily on small flies. Adults overwintered within fallen leaves on the bluff outcroppings, emerged in early April, and began feeding and reproducing shortly thereafter. Eggs were found from early May to late October and were deposited on the leaves and stems of Heuchera parviflora Bartling. Nymphs were found from early June to early September. New adults appeared in mid-July and remained active until early October. This species was reared in the laboratory on adult Drosophila sp. at $26 \pm 3.0^{\circ} \mathrm{C}$ under a photoperiod of 16:8 (L:D) h. The incubation period averaged $13.25 \mathrm{~d}$; eyespots appeared in $\approx 7 \mathrm{~d}$. The five stadia averaged $11.86,11.77,12.44,15.35$, and $18.88 \mathrm{~d}$, respectively. The instars can be distinguished by differences in several anatomical features including body length and width.
\end{abstract}

KEY WORDS Pseudometapterus umbrosus, life history, laboratory rearing, descriptions, nymphs

THE EMESINE REDUVIIDS, a group of assassin bugs with slender bodies and appendages, have a cosmopolitan distribution (Wygodzinsky 1966). Although these predaceous insects occur throughout North America, they usually are not collected in large numbers. As a result, the biology of most species is poorly known (McPherson 1991a). Emesines are known to occur beneath loose bark; in bases of tufts of grasses; in bunches of dead leaves; in barns, dwellings, cellars, and outhouses (Blatchley 1926); at considerable heights on bushes and trees; within caves; and in association with "psocid" and spider webs (Wygodzinsky 1966).

Pseudometapterus Wygodzinsky, an emesine genus, contains 15 species, all with a Nearctic or Neotropical distribution (Wygodzinsky 1966). Of these, three occur in America north of Mexico: P. butleri Wygodzinsky in Arizona, P. wygodzinskyi (Elkins) in Texas, and P. umbrosus (Blatchley) in Florida (Froeschner 1988) and Illinois (McPherson 1991a).

The discovery of $P$. umbrosus in Illinois was based on two male adults deposited in the Southern Illinois University Entomology Collection. They had been collected on 27 July 1972 from the LaRue-Pine Hills Ecological Area (now LaRue-Pine Hills Research Natural Area), Union County, a dramatic extension of this

\footnotetext{
${ }^{1}$ Current address: Department of Entomology, Iowa State University, 103 Insectary, Ames, IA 50011-0001 (e-mail: mcpherson@ zoology.siu.edu).
}

emesine's previously known Florida distribution (McPherson 1991a, 1991b). The only life history information then available was that it had been beaten from fallen leaves of a royal palm in a dense hammock on Paradise Key, FL (Blatchley 1926), and collected from Spanish moss (Wygodzinsky 1966).

Hagerty and McPherson (1999) reported on a survey of the assassin bugs of southern Illinois, including P. umbrosus. They collected adults of this species from spider webs and plants (i.e., Heuchera parviflora Bartling) on sandstone bluffs $(n=41)$ and on spider webs on limestone bluffs $(n=2)$ in Jackson and Union counties, respectively. Specimens were taken from 13 April to 24 November, but most $(69.8 \%, n=30)$ were collected during August and September; these data suggest this species is univoltine and overwinters as adults.

The population in Jackson County was discovered in Little Grand Canyon, which lies $14.5 \mathrm{~km} \mathrm{SW}$ of Murphysboro within the Shawnee National Forest. Little Grand Canyon spans 555.2 ha and consists of ridge tops sloping to large Pennsylvanian sandstone bluffs. The bluffs, in turn, encompass a 1,676.4 m long canyon that reaches a depth of $33.5 \mathrm{~m}$ (Hopkins and Simon 1975, Mohlenbrock 1977). Flora on the ridge tops and slopes consists mostly of a mesic upland community of white oak (Quercus alba L.), red oak (Quercus rubra L.), black oak (Quercus velutina Lamarck), shagbark hickory [Carya ovata (Miller)], and pignut hickory (Carya glabra Miller) (Mohlen- 
brock 1977). The canyon floor flora consists mostly of a mesic lowland community of beech (Fagus grandifolia Ehrhart) and tulip poplar (Liriodendron tulipifera L.) (Mohlenbrock 1977).

The study site, within a chute of Little Grand Canyon, is located in the Gorham quadrangle $7.5^{\prime}$ series (topographic) (T10S, R3W, W1/2 of NW1/4 of section 1). The ridge slopes at this location support a mesic upland community of black oak, shagbark hickory, false shagbark [C. ovalis (Wangenheim)], and black maple (Acer nigrum Michaux f.). The bluff faces support communities of alumroot (H. parviflora), christmas fern [Polystichum acrostichoides (Michaux)], marginal shield-fern [Dryopteris marginalis (L.)], mosses [e.g., Leucobryum glaucum (Hedwig) Ångström, Atichum angustatum (Bridel) Buchner and Shimper, Tetraphis pullucida Hedwig, and Bryoandersonia recognitum (Hedwig) Lindberg], and a leafy liverwort (Isotachis sp.). The chute supports a temporary rain-fed stream that sustains persistent water pools on the streambed.

In this article, we present further information on the field life history of P. umbrosus in Little Grand Canyon and include information on laboratory rearing and descriptions of the immature stages.

\section{Materials and Methods}

Life History. The field study of P. umbrosus was conducted from February 1999 to November 2000. The first year we determined the feasibility of the study. These insects are difficult to see because of their slender bodies and appendages, relatively small size (e.g., first instars averaged $<3.60 \mathrm{~mm}$ in length [unpublished data]), and general inactivity. However, we found that individuals tended to congregate on the small sandstone outcroppings of the bluffs, making their detection easier. Thus, we conducted a detailed study during 2000 . The study site was restricted to two areas ( 14.0 by $2.4 \mathrm{~m}, 20$ by $2.4 \mathrm{~m}$ ) on the chute walls separated by $140 \mathrm{~m}$.

Counts of nymphs and adults and notes on insect activities were taken weekly from early February to early November, before the bugs emerged from and after they entered overwintering sites. Specimens were collected by handpicking but generally were released to prevent overcollecting. Those that could not be identified to instar were preserved in $70 \% \mathrm{EtOH}$ and examined in the laboratory. Prey (defined as individuals held by prothoracic legs) were collected and preserved in $70 \% \mathrm{EtOH}$. Potential overwintering sites (e.g., leaf litter) were examined periodically from early October 1999 to early April 2000.

Laboratory Rearing. Seven adults were collected on 6 November 1999 from beneath leaves at Little Grand Canyon, brought to the laboratory, and placed in four ovipositional cages (three cages, one male, one female; one cage, one female). Each cage consisted of a 1-pt ( $\approx 0.47$-liter) Mason jar with a disc of moistened filter paper on the bottom; it was closed with discs of paper toweling and wire screening secured with the band of the two-piece Mason jar lid. A strip of paper toweling ( $\approx 11.4 \mathrm{~cm}$ long, $6.0 \mathrm{~cm}$ wide), folded longitudinally to prevent the strip from rolling up when damp, was suspended inside the jar and secured at the upper end between the discs of toweling and screening. This strip increased surface area for walking and absorption of excrement.

The cages were examined daily for eggs, which were removed and placed on moistened filter paper (EatonDikeman, grade 613, Mount Holly Springs, PA) on the bottom of a petri dish $(\approx 9 \mathrm{~cm}$ diameter, $2.0 \mathrm{~cm}$ deep) and covered with the lid.

Newly emerged first instars were placed on moistened filter paper in petri dishes prepared similarly to those for eggs except that each dish was closed with a piece of interlock cloth (2-mm ${ }^{2}$ mesh) secured with the lid. The cloth provided additional surface area for walking and molting; nymphs were unable to molt successfully unless suspended upside down from the cloth. No more than two nymphs were placed in each dish to reduce the risk of cannibalism. Nymphal pairs were separated at subsequent molts as necessary to allow individual records of development.

The numbers of nymphs completing the fourth and fifth stadia were low. Therefore, we supplemented these data with field-collected third instars that were reared to adults under the same conditions as nymphs reared from eggs to adults.

Eggs, nymphs, and adults were kept in incubators maintained at $26 \pm 3.0^{\circ} \mathrm{C}$ and a photoperiod of $16: 8$ $(\mathrm{L}: \mathrm{D}) \mathrm{h}(\approx 2,800$ lux $)$. Filter paper in the ovipositional cages and petri dishes was moistened daily. Adults were fed 9-11, nymphs 5-10, wingless, debilitated Drosophila sp. adults per day.

Descriptions of Immature Stages. The description of each stage is based on 10 field-collected individuals preserved in $70 \%$ ethanol. Drawings were made with a Wild MSA drawing tube (E. Leitz, Rockleigh, NJ), measurements (in millimeters) with an ocular micrometer. Scanning electron micrographs were used as aids in the descriptions of the egg and first instar.

Statistics. Averages are expressed as means $\pm \mathrm{SE}$; standard errors of $<0.005$ are listed as 0.00 . Fieldcollected and laboratory-reared third instars were reared to adults and their fourth and fifth stadia compared with a Mann-Whitney $U$ test; level of significance was 0.01 . The statistical test was chosen primarily because the samples were small and of unequal size.

\section{Results and Discussion}

Life History. Pseudometapterus umbrosus overwintered as adults within piles of leaves that had fallen from the slope overhead and accumulated around the bases of plants (e.g., P. acrostichoides) on bluff outcroppings $(n=3$ adults [30 October 1999]; $n=7$ [6 November 1999]; $n=2$ [13 November 1999]; $n=1$ [ 5 February 2000]). They emerged in early April and began feeding and copulating shortly thereafter. Copulation (13 pairs) was observed from early May to early June on bare rock outcroppings, or on plants attached to outcroppings, on the bluff face. On one occasion, a male attempted to copulate with a female 


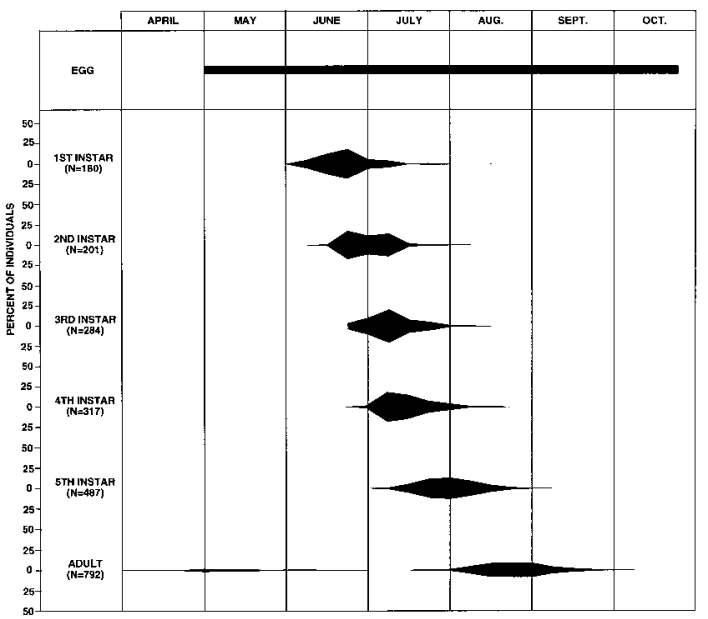

Fig. 1. Field life cycle of $P$. umbrosus. Percentage in each sample of total individuals of same stage collected during the 2000 season at Little Grand Canyon, Jackson County, IL. Bar for eggs only indicates presence.

already in copula. It attempted to dislodge the copulating male by nudging its abdomen; unsuccessful, the intruding male left.

Eggs were found from early May to late October (Figs. 1 and 2). However, because fertile, infertile, and hatched eggs could not be distinguished easily, seasonal changes in ovipositional frequency could not be determined. Eggs were deposited singly on the leaves and stems of $H$. parviflora with an ovipositional time of $\approx 1-3$ min. On one occasion, a female was observed with her metathoracic legs on the bare rock face of the bluff and mesothoracic legs grasping and pulling an attached H. parviflora leaf (the role of her prothoracic legs was unclear, although she appeared to be stroking the leaf with them). As she did so, she touched the tip

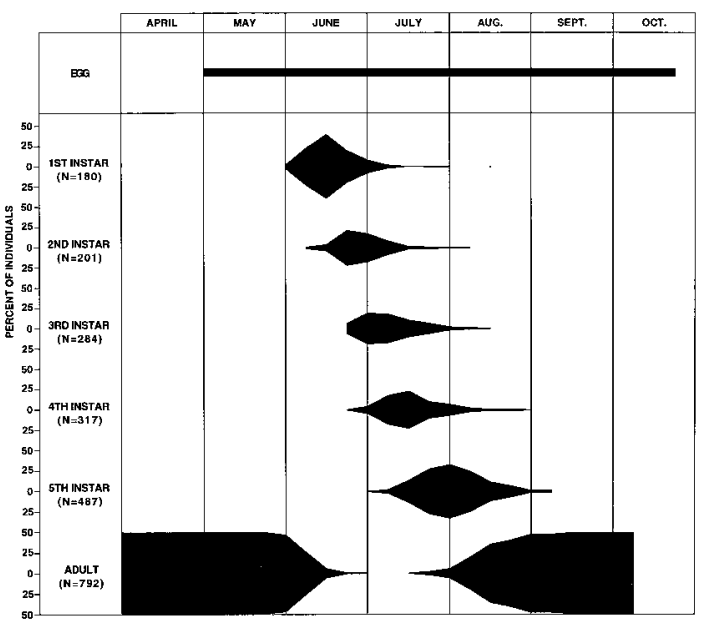

Fig. 2. Field life cycle of $P$. umbrosus. Percentage in each sample of individuals of each stage collected during the 2000 season at Little Grand Canyon, Jackson County, IL. Bar for eggs only indicates presence.
Table 1. Feeding records of $P$. umbrosus in Little Grand Canyon, Jackson County, IL, during 1999 and 2000

\begin{tabular}{|c|c|}
\hline Taxon & $\begin{array}{c}\text { No. of } \\
\text { specimens }\end{array}$ \\
\hline \multicolumn{2}{|l|}{ Araneida } \\
\hline \multicolumn{2}{|l|}{ Theridiosomatidae } \\
\hline Theridiosoma gemmosum $(\text { L. Koch })^{a}$ & 1 \\
\hline \multicolumn{2}{|l|}{ Theridiidae } \\
\hline Achaearanea sp. ${ }^{a}$ & 1 \\
\hline \multicolumn{2}{|l|}{ Collembola } \\
\hline \multicolumn{2}{|l|}{ Entomobryidae } \\
\hline Tomocerus minor (Lubbock) $)^{b}$ & 2 \\
\hline \multicolumn{2}{|l|}{ Lepidoptera } \\
\hline \multicolumn{2}{|l|}{ Tineidae } \\
\hline Chloropleca sp. ${ }^{c}$ (species undescribed) & 1 \\
\hline \multicolumn{2}{|l|}{ Diptera } \\
\hline Ceratopogonidae $^{c}$ & 3 \\
\hline Palpomyia sp. ${ }^{c}$ & 1 \\
\hline \multicolumn{2}{|l|}{ Mycetophilidae } \\
\hline Trichonta sp. ${ }^{c}$ & 1 \\
\hline Cecidomyiidae $^{c}$ & 12 \\
\hline \multicolumn{2}{|l|}{ Chironomidae } \\
\hline \multicolumn{2}{|l|}{ Orthocladinae } \\
\hline Thienemaniella xena Roback $^{c}$ & 1 \\
\hline \multicolumn{2}{|l|}{ Chironominae } \\
\hline Chironomini $^{c}$ & 1 \\
\hline \multicolumn{2}{|l|}{ Tanypodinae } \\
\hline Pentaneurini $^{c}$ & 1 \\
\hline Tipulidae $^{c}$ & 1 \\
\hline Limonia sp. ${ }^{c}$ & 2 \\
\hline Limonia (Dicranomyia) $\mathrm{sp}^{c}$ & 1 \\
\hline \multicolumn{2}{|l|}{ Drosophilidae } \\
\hline \multirow{2}{*}{\multicolumn{2}{|c|}{$\begin{array}{l}\text { Drosophila sp. } \\
\text { Sciaridae }\end{array}$}} \\
\hline & \\
\hline Lycoriella sp. ${ }^{c}$ & 1 \\
\hline \multicolumn{2}{|l|}{ Culicidae } \\
\hline Culex restuans Theobald $^{c}$ & 1 \\
\hline
\end{tabular}

\footnotetext{
${ }^{a}$ Immature

${ }^{b}$ Subadult or adult.

${ }^{c}$ Adult.
}

of her abdomen to the underside of the leaf and deposited an egg. Two adult males were found with an egg attached to their metathoracic legs.

First instars were found primarily from early June to late July, second instars from early June to early August, third instars from late June to mid-August, fourth instars from late June to late August, fifth instars from early July to early September, and adults from early April to late June and mid-July to early October (Figs. 1 and 2).

Adults were found on cribellate $(n=166)$ and noncribellate $(n=7)$ spider webs, on leaves and stems of $H$. parviflora $(n=238)$, within dead fronds of $P$. acrostichoides $(n=6)$, and on the barren substrate interspersed with patches of mosses and lichens $(n=$ 308). Nymphs were observed on webs of cribellate spiders $(n=847)$, bare substrate interspersed with patches of mosses and lichens $(n=320)$, and leaves and stems of $H$. parviflora $(n=251)$.

Pseudometapterus umbrosus preyed on a variety of small arthropods but preferred flies, particularly cecidomyiids (Table 1 ). On one occasion, a noncribellate spider, Achaearanea tepidariorum (Koch), was observed feeding on a fifth instar. On another occasion, an adult male was observed with its beak inserted into a dead flower of $H$. parviflora. 
Table 2. Duration (in days) of each immature stage of $P$. umbrosus under controlled laboratory conditions

\begin{tabular}{lcccc}
\hline \hline Stage & $\begin{array}{c}\text { No. } \\
\text { completing } \\
\text { stadium }\end{array}$ & Range & Mean $\pm \mathrm{SE}$ & $\begin{array}{c}\text { Cumulative } \\
\text { mean age }\end{array}$ \\
\hline Egg $^{a}$ & 122 & $9-15$ & $13.25 \pm 0.09$ & 13.25 \\
Nymph $^{b}$ & 72 & $7-24$ & $11.86 \pm 0.39$ & 25.11 \\
$\quad$ 1st instar & 39 & $7-30$ & $11.77 \pm 0.79$ & 36.88 \\
2nd instar & 27 & $7-21$ & $12.44 \pm 0.77$ & 49.32 \\
3rd instar & 17 & $9-25$ & $15.35 \pm 1.14^{c}$ & 64.67 \\
4th instar & 8 & $10-31$ & $18.88 \pm 2.64^{d}$ & 83.55 \\
5th instar & 16 & $6-18$ & $10.81 \pm 0.98^{c}$ & - \\
Nymph & & $9-17$ & $11.44 \pm 0.56^{d}$ & - \\
4th instar & 16 & & &
\end{tabular}

${ }^{a} 359$ eggs were laid.

${ }^{b}$ Reared from egg.

${ }^{c}$ Significantly different; Mann-Whitney $U=56.5, P=0.002$

${ }^{d}$ Significantly different; Mann-Whitney $U=18.5, P=0.003$.

${ }^{e}$ Field-collected as third instars.

Pseudometapterus umbrosus is univoltine in southern Illinois as evidenced by the peaks in abundance of the adults and nymphs (Figs. 1 and 2).

Laboratory Rearing. The three pairs of overwintered adults reproduced, with the females depositing 86,92 , and 181 eggs of which 23,46 , and 53 hatched, respectively. The unpaired female laid 41 eggs, but none hatched.

Eggs were laid singly and affixed laterally, usually to the lid or paper toweling but occasionally to the filter paper or sides of the cages. The incubation period averaged 13.25 d (Table 2). The egg was yellowish brown with a smooth chorion, usually with attached longitudinal, white flanges, and capped by a reticulated operculum (Fig. 3). Red eyespots were visible after $\approx 7 \mathrm{~d}$ ( range $=4-9 ; n=129)$.

The first instar emerged through a cephalic slit in the chorion, pushing aside the operculum. It was

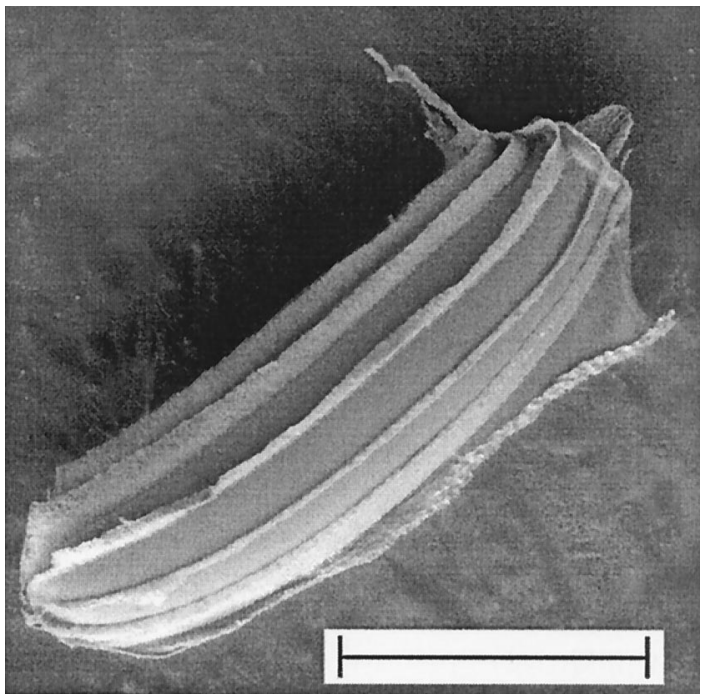

Fig. 3. Scanning electron micrograph of egg of P. umbrosus (scale bar $=0.5 \mathrm{~mm}$ ). white, almost transparent upon emerging, and darkened only after feeding.

The first, second, third, fourth, and fifth stadia averaged 11.86, 11.77, 12.44, 15.35, and $18.88 \mathrm{~d}$, respectively. The total developmental period averaged $83.55 \mathrm{~d}$ (Table 2). Highest mortality occurred during the second stadium, primarily resulting from incomplete ecdysis.

Comparisons of the fourth and fifth stadia of laboratory-reared and field-collected third instars showed that each stadium was shorter for field-collected individuals (Table 2). This strongly suggests that Drosophila sp. was not an ideal food source, at least for young instars.

Adults appeared to drink water from the filter paper 2-5 min after the paper was moistened. They also fed upon adults of Drosophila sp. within 15 min after flies had been introduced.

Precopulatory behavior was observed on the lid, paper toweling, and filter paper. Courtship began with the male approaching the female from behind, periodically antennating her abdomen and meta- and mesothoracic legs before mounting her. He then grasped the lateral margin of her pro- or mesothorax with his prothoracic legs. At this point, his abdomen crossed hers diagonally. He lowered the tip of his abdomen so that his genitalia came in contact with hers, and copulation ensued. Copulation $(n=11)$ sometimes continued for more than $4 \mathrm{~h}$.

Descriptions of Immature Stages. Egg. (Fig. 3). Length, $1.61 \pm 0.01$; width at widest point (usually near middle), $0.40 \pm 0.00$. Egg curviform, comprised of egg proper (length, 1.46 \pm 0.01 ) and operculum (length, $0.14 \pm 0.00$; diameter, $0.26 \pm 0.00$ ). Eggs laid singly, yellowish brown, glued laterally to substrate, this side convex, opposite side straight. Chorion generally smooth, usually with $\approx 12$ attached, longitudinal, white (translucent in alcohol) flanges fused at base of egg and extending anteriorly beyond base of operculum; operculum with reticulate pattern, central area projecting as distinct cone.

Instars. The first instar is described in detail, but only major changes from previous instars are recorded for subsequent instars. Length is measured from tip of anteclypeus to tip of abdomen, width across the projecting posterior lobes of the metaepisterna. Additional measurements are given in Table 3.

First Instar (Fig. 4). Length, $3.31 \pm 0.03$; width, $0.39 \pm 0.01$. Body slender, elongate. General ground color of head (including beak), thorax, and abdomen white to yellowish white; body shiny, with brown dorsolateral and lateral longitudinal stripes on head and thorax; antennae, meso-, and metathoracic legs brown with white to yellowish white annuli, prothoracic legs with less brown.

Head broadly fusiform, narrowed anteriorly and posteriorly, longer than wide. Antenniferous tubercles weakly divergent anteriorly; width of head across apical margin of tubercles subequal to synthlipsis. Pair of dorsolateral, longitudinal, discontinuous, brown stripes extending from antenniferous tubercles to almost posterior margin of head; stripes interrupted at 
Table 3. Measurements (mean \pm SE mm) of $P$. umbrosus instars

\begin{tabular}{|c|c|c|c|c|c|}
\hline & \multicolumn{5}{|c|}{ Nymph } \\
\hline & 1st instar & 2nd instar & 3rd instar & 4th instar & 5th instar \\
\hline Body length $^{a}$ & $3.31 \pm 0.03$ & $5.41 \pm 0.05$ & $7.49 \pm 0.05$ & $10.51 \pm 0.16$ & $15.35 \pm 0.32$ \\
\hline Head length ${ }^{a}$ & $0.44 \pm 0.00$ & $0.54 \pm 0.01$ & $0.64 \pm 0.01$ & $0.78 \pm 0.01$ & $1.04 \pm 0.02$ \\
\hline Anterior lobe & $0.21 \pm 0.00$ & $0.29 \pm 0.01$ & $0.35 \pm 0.01$ & $0.41 \pm 0.01$ & $0.56 \pm 0.01$ \\
\hline Posterior lobe & $0.23 \pm 0.00$ & $0.27 \pm 0.01$ & $0.29 \pm 0.01$ & $0.37 \pm 0.01$ & $0.48 \pm 0.02$ \\
\hline Width across eyes & $0.26 \pm 0.00$ & $0.30 \pm 0.00$ & $0.33 \pm 0.00$ & $0.41 \pm 0.01$ & $0.53 \pm 0.01$ \\
\hline Synthlipsis & $0.22 \pm 0.00$ & $0.25 \pm 0.00$ & $0.27 \pm 0.00$ & $0.30 \pm 0.01$ & $0.39 \pm 0.01$ \\
\hline Antennal segments & $4.55 \pm 0.04$ & $6.16 \pm 0.08$ & $7.67 \pm 0.10$ & $10.29 \pm 0.09$ & $13.89 \pm 0.17$ \\
\hline 1st & $1.83 \pm 0.02$ & $2.57 \pm 0.03$ & $3.26 \pm 0.04$ & $4.49 \pm 0.05$ & $6.15 \pm 0.09$ \\
\hline 2nd & $1.23 \pm 0.01$ & $1.91 \pm 0.03$ & $2.64 \pm 0.04$ & $3.77 \pm 0.04$ & $5.28 \pm 0.08$ \\
\hline $3 \mathrm{rd}$ & $0.17 \pm 0.00$ & $0.19 \pm 0.00$ & $0.21 \pm 0.00$ & $0.24 \pm 0.00$ & $0.31 \pm 0.01$ \\
\hline 4th & $1.32 \pm 0.01$ & $1.49 \pm 0.02$ & $1.56 \pm 0.03$ & $1.79 \pm 0.02$ & $2.15 \pm 0.02$ \\
\hline Beak segments & $0.47 \pm 0.01$ & $0.60 \pm 0.01$ & $0.69 \pm 0.01$ & $0.83 \pm 0.03$ & $1.22 \pm 0.02$ \\
\hline lst & $0.13 \pm 0.00$ & $0.18 \pm 0.01$ & $0.21 \pm 0.01$ & $0.27 \pm 0.01$ & $0.42 \pm 0.02$ \\
\hline 2nd & $0.12 \pm 0.00$ & $0.16 \pm 0.00$ & $0.19 \pm 0.00$ & $0.23 \pm 0.00$ & $0.35 \pm 0.00$ \\
\hline 3 rd & $0.22 \pm 0.01$ & $0.26 \pm 0.00$ & $0.29 \pm 0.00$ & $0.33 \pm 0.01$ & $0.45 \pm 0.01$ \\
\hline Notal lengths ${ }^{b}$ & $0.94 \pm 0.01$ & $1.48 \pm 0.02$ & $2.03 \pm 0.01$ & $2.87 \pm 0.04$ & $4.30 \pm 0.07$ \\
\hline Pronotum & $0.34 \pm 0.00$ & $0.56 \pm 0.01$ & $0.80 \pm 0.01$ & $1.18 \pm 0.02$ & $1.78 \pm 0.03$ \\
\hline Mesonotum & $0.33 \pm 0.00$ & $0.52 \pm 0.01$ & $0.68 \pm 0.01$ & $0.91 \pm 0.02$ & $1.32 \pm 0.02$ \\
\hline Metanotum & $0.27 \pm 0.00$ & $0.40 \pm 0.00$ & $0.55 \pm 0.01$ & $0.78 \pm 0.01$ & $1.20 \pm 0.02$ \\
\hline Width across metaepisterna & $0.39 \pm 0.01$ & $0.42 \pm 0.01$ & $0.46 \pm 0.01$ & $0.58 \pm 0.01$ & $0.77 \pm 0.02$ \\
\hline Abdominal length ${ }^{b}$ & $1.94 \pm 0.03$ & $3.48 \pm 0.04$ & $4.82 \pm 0.04$ & $6.81 \pm 0.12$ & $10.01 \pm 0.23$ \\
\hline \multicolumn{6}{|l|}{ Leg lengths } \\
\hline Procoxa & $0.58 \pm 0.01$ & $0.79 \pm 0.01$ & $0.99 \pm 0.01$ & $1.39 \pm 0.01$ & $2.06 \pm 0.04$ \\
\hline Protrochanter & $0.19 \pm 0.01$ & $0.27 \pm 0.01$ & $0.33 \pm 0.01$ & $0.37 \pm 0.01$ & $0.48 \pm 0.01$ \\
\hline Profemur & $0.88 \pm 0.01$ & $1.15 \pm 0.02$ & $1.45 \pm 0.02$ & $1.97 \pm 0.02$ & $2.92 \pm 0.05$ \\
\hline Protibia & $0.42 \pm 0.01$ & $0.55 \pm 0.01$ & $0.60 \pm 0.01$ & $0.81 \pm 0.01$ & $1.07 \pm 0.02$ \\
\hline Protarsus & $0.28 \pm 0.00$ & $0.33 \pm 0.00$ & $0.36 \pm 0.00$ & $0.47 \pm 0.01$ & $0.66 \pm 0.01$ \\
\hline Mesocoxa & $0.17 \pm 0.00$ & $0.21 \pm 0.00$ & $0.24 \pm 0.01$ & $0.31 \pm 0.00$ & $0.48 \pm 0.01$ \\
\hline Mesotrochanter & $0.17 \pm 0.01$ & $0.21 \pm 0.01$ & $0.24 \pm 0.01$ & $0.29 \pm 0.00$ & $0.39 \pm 0.01$ \\
\hline Mesofemur & $1.78 \pm 0.03$ & $2.41 \pm 0.04$ & $3.05 \pm 0.03$ & $4.21 \pm 0.05$ & $6.01 \pm 0.08$ \\
\hline Mesotibia & $2.53 \pm 0.02$ & $3.37 \pm 0.05$ & $4.10 \pm 0.06$ & $5.61 \pm 0.08$ & $7.80 \pm 0.09$ \\
\hline Mesotarsus & $0.29 \pm 0.01$ & $0.32 \pm 0.00$ & $0.32 \pm 0.01$ & $0.38 \pm 0.01$ & $0.47 \pm 0.02$ \\
\hline 1 st & $0.09 \pm 0.00$ & $0.11 \pm 0.00$ & $0.12 \pm 0.00$ & $0.14 \pm 0.00$ & $0.19 \pm 0.01$ \\
\hline 2nd & $0.20 \pm 0.00$ & $0.21 \pm 0.00$ & $0.20 \pm 0.01$ & $0.23 \pm 0.00$ & $0.30 \pm 0.01$ \\
\hline Metacoxa & $0.18 \pm 0.00$ & $0.23 \pm 0.00$ & $0.27 \pm 0.01$ & $0.35 \pm 0.01$ & $0.49 \pm 0.01$ \\
\hline Metatrochanter & $0.18 \pm 0.01$ & $0.23 \pm 0.00$ & $0.25 \pm 0.01$ & $0.33 \pm 0.01$ & $0.44 \pm 0.01$ \\
\hline Metafemur & $2.10 \pm 0.02$ & $2.89 \pm 0.05$ & $3.70 \pm 0.05$ & $5.22 \pm 0.07$ & $7.56 \pm 0.10$ \\
\hline Metatibia & $3.11 \pm 0.02$ & $4.12 \pm 0.06$ & $5.15 \pm 0.07$ & $7.26 \pm 0.15$ & $10.31 \pm 0.10$ \\
\hline Metatarsus & $0.29 \pm 0.01$ & $0.32 \pm 0.00$ & $0.33 \pm 0.00$ & $0.38 \pm 0.00$ & $0.51 \pm 0.01$ \\
\hline 1 st & $0.09 \pm 0.00$ & $0.11 \pm 0.00$ & $0.12 \pm 0.00$ & $0.15 \pm 0.00$ & $0.19 \pm 0.01$ \\
\hline 2nd & $0.20 \pm 0.00$ & $0.21 \pm 0.00$ & $0.21 \pm 0.00$ & $0.24 \pm 0.00$ & $0.32 \pm 0.01$ \\
\hline
\end{tabular}

Data based on 10 individuals per instar.

${ }^{a}$ Meaured from tip of anteclypeus.

${ }^{b}$ Measured at midline.

posterior margin of middorsal transverse sulcus that continues anterolaterad, ending anterior to eyes; sulcus dividing head into anterior and posterior lobes, anterior lobe $\approx 0.91$ times length of posterior lobe; posterior lobe distinctly elevated above anterior lobe, anterior margin occasionally concave medially. Tylus greatly surpassing juga, divided into obscure anteclypeus and longer postclypeus; postclypeus with transverse, brown band anteriorly; juga short, sloping laterad, not reaching distal margins of antenniferous tubercles. Labrum elongate, digitiform, declivent. Ventrolateral brown stripe extending each side from antenniferous tubercle to almost posterior margin of head, stripes interrupted by small, granular, red compound eyes. Beak three-segmented, brown laterally, tip fitting into prosternal, striated groove; segments 1 and 2 subequal, segment 3 longest, narrowing apically. Antennae 4-segmented, filiform, annulated with white at intersegmental lines; total length $\approx 10.34$ times length of head; segment 1 longest, swollen basally; segment 2 with subapical trichobothrium dorsally; segment 3 shortest; segment 4 acute apically, more heavily setose than preceding segments, length of setae subequal to longer than width of segment; ratio of antennal segment lengths $\approx 10.77: 7.24: 1.00: 7.77$.

Thorax elongate, narrowest at juncture of pro- and mesothoraces; ratio of notal lengths to body width ( see definition $) \approx 0.87: 0.85: 0.69$; nota with pair of dorsolateral, brown stripes extending from anterior margin of pronotum to posterior margin of metanotum; dorsomedial white stripe occasionally present, extending from anterior margin of mesonotum almost to apex of abdomen. Prothorax subtrapezoidal, narrowed posteriorly; notum weakly overlapping mesonotum posteriorly, posterolateral margin distinctly separated from prospiracular swelling. Mesothorax subtrapezoidal, narrowed anteriorly. Metathorax broadly subtrapezoidal, narrowed anteriorly. Thoracic spiracles present, directed laterad, peritremes brown; spiracle 1 near posterior margin of proepimeron, spiracle 2 near 


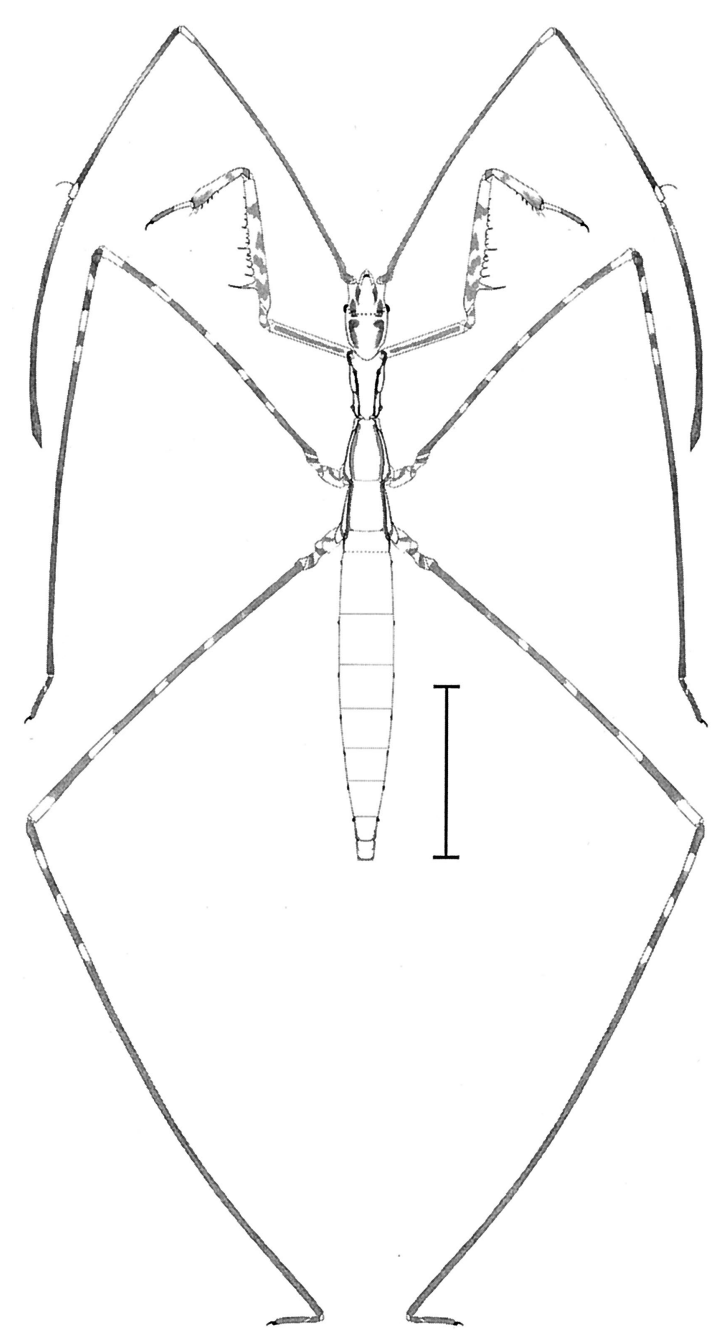

Fig. 4. First instar (general dorsal view) of P. umbrosus (scale bar $=1 \mathrm{~mm})$.

posterior margin of mesoepimeron. Pleura with lateral and ventrolateral brown stripes extending from anterior margin of propleuron to posterior margin of metapleuron; lateral stripe touching dorsolateral stripe at anterior and posterior margins of propleuron and posterior margin of mesopleuron, sometimes also touching near middle of propleuron and anterior margin of mesopleuron; ventrolateral stripe discontinuous, extending from anterior margin of propleuron to posterior margin of metapleuron. Prothoracic legs raptorial, spinose (Figs. 4 and 13). Procoxae elongate with lateral longitudinal brown stripe. Protrochanters elbowed with short brown bands proximally and distally. Profemora with antero- and posteroventral longitudinal rows of 8-11 and 12-14 spines, respectively; anteroventral row interrupted basally, continued as single spine basad of interruption; posteroventral row continuous, terminating basally in large spine, basal spine of anteroventral row not located basad of this large spine; irregular brown markings on posterior surface; spines with tips dark brown; large basal spine with distal two-thirds often brown. Protibiae short, swollen and setose apically; anteroventral longitudinal row of 3-5 minute spines apically; setae ventrally encompassing diagonal, setose, comblike structure; brown basal, subbasal, and apical annuli present. Protarsi 1-segmented, brown apically, with single brown claw. Meso- and metathoracic legs narrow, elongate; coxae globose, often with diagonal brown band; trochanters similar in shape and color to protrochanters; femora and tibiae brown with white to yellowish white annuli; tarsi 2-segmented, brown, segments separated by white membranous area; tarsal claws (2) brown, each with medial tooth.

Abdomen apparently 9-segmented, generally appearing membranous; intersegmental lines difficult to distinguish, that of segments 1 and 2 obscure; segment 1 apparently shorter and segment 2 apparently longer than each of remaining segments. Tergum 1 apparently overlapping tergum 2 , laterally with brown band reaching anterior margin of spiracle 2; sternum 2 with pair of anterior, submedial brown marks. Sternum 7 with pair of posterior, submedial brown marks. Segment 8 with one lateral and one ventrolateral pair of brown bands. Segment 9 brown ventrally with apical brown annulus to completely brown but if not completely brown, then with pair of lateral brown bands that merge posteriorly with annulus. Dorsal and ventral white, discontinuous, longitudinal bands and irregular markings occasionally present submedially on dorsal and ventral surfaces. Eight pairs of abdominal spiracles present, peritremes brown; pair 1 dorsolateral, pairs 2-8 lateral.

Second Instar (Fig. 5). Length, $5.41 \pm 0.05$; width, $0.42 \pm 0.01$. Body with sparse setigerous pustules on head laterally, thoracic pleura, and abdomen. Head with anterior lobe $\approx 1.07$ times length of posterior lobe; posterior lobe less elevated above anterior lobe. Antennae $\approx 11.41$ times length of head. Ratio of antennal segment lengths $\approx 13.53: 10.05: 1.00: 7.84$.

Thorax more elongate, ratio of notal lengths to body width $\approx 1.33: 1.24: 0.95$. Pronotum less flattened, more noticeably overlapping mesonotum, posterolateral margin closer to prospiracular swelling; sternum with pair of submedial, irregular longitudinal rows of 5-12 setigerous, brown pustules. Meso- and metanota with wing pads evident, weakly developed. Prothoracic legs (Fig. 14) more spinose; femora with antero- and posteroventral longitudinal rows of 10-13 and 14-19 spines, respectively; tibiae with anteroventral longitudinal row of 9-13 spines, now extending length of tibia.

Abdomen with pair of discontinuous, longitudinal brown bands dorsolaterally, ventrally, and, often, on terga 5 and 6 . Medial brown stripe present on terga $7-8$, interrupted at intersegmental line of 7 and 8 . Tergum 9 mostly brown. Dorso- and ventromedial, white, continuous, longitudinal stripes occasionally present; dorsomedial stripe extending from posterior margin of metanotum (occasionally continuous with dorsomedial stripe of thorax) to, at most, tergum 7; 


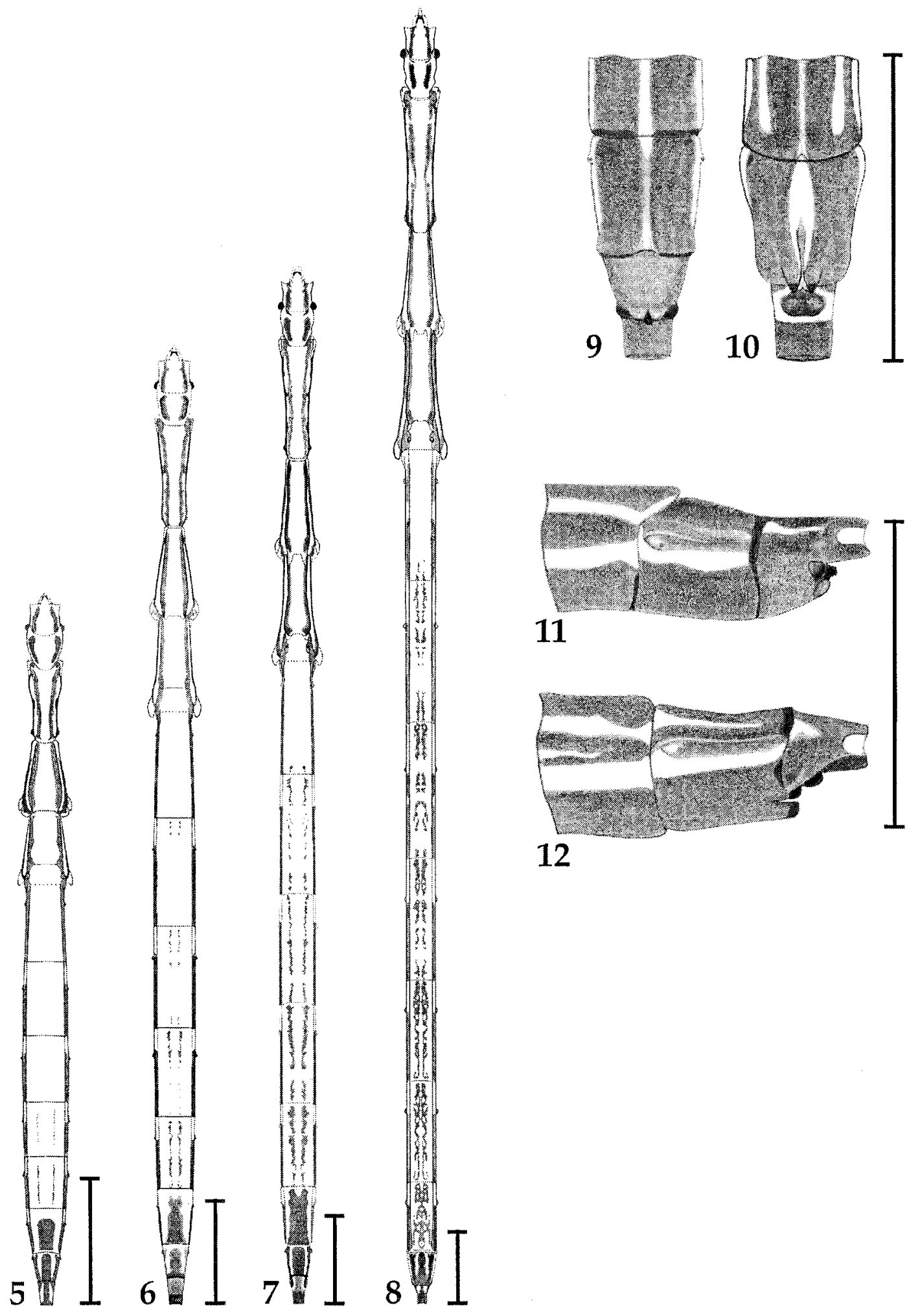

Figs. 5-12. Second-fifth instars of P. umbrosus (scale bars $=1 \mathrm{~mm}$ ). General dorsal view (5-8). 5. Second instar. 6. Third instar. 7. Fourth instar. 8. Fifth instar. Terminalia, fifth instar (9-12). 9. Male, ventral view. 10. Female, ventral view. 11. Male, lateral view. 12. Female, lateral view. 

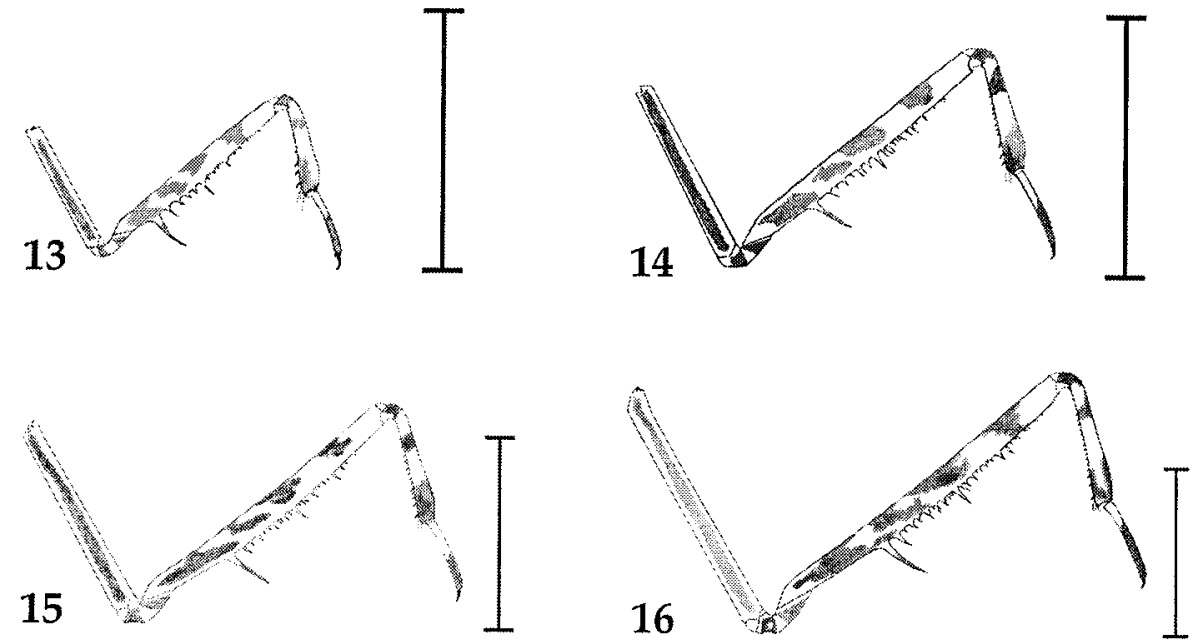

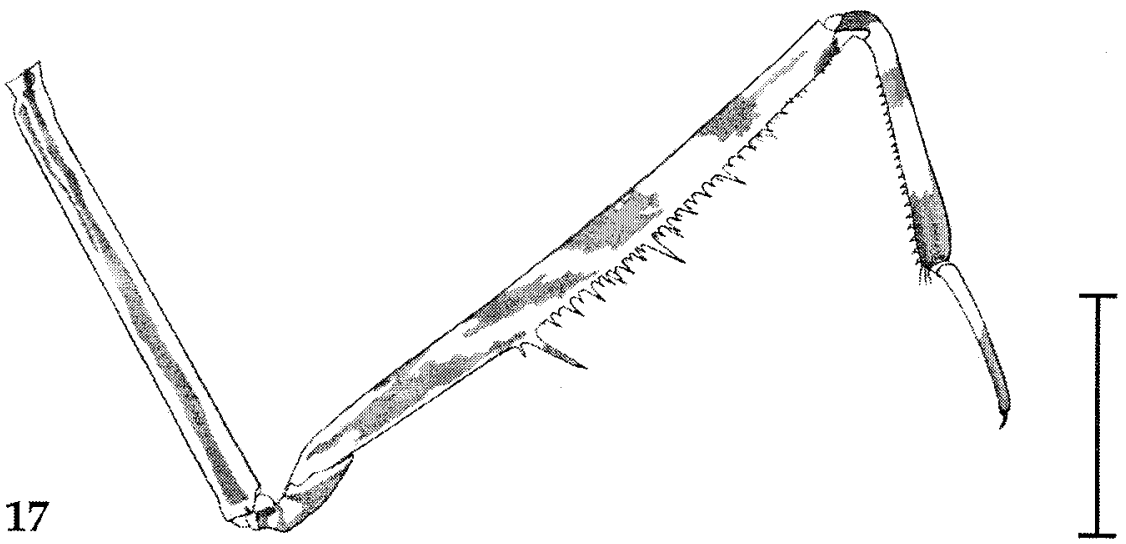

Figs. 13-17. Prothoracic legs of P. umbrosus (scale bars $=1 \mathrm{~mm}$ ). 13. First instar. 14. Second instar. 15 . Third instar. 16. Fourth instar. 17. Fifth instar.

ventromedial stripe extending from posterior margin of metasternum to sternum 8 .

Third Instar (Fig. 6). Length, $7.49 \pm 0.05$; width, $0.46 \pm 0.01$. Body with more setigerous pustules. Head with middorsal transverse sulcus more evident laterally; anterior lobe $\approx 1.21$ times length of posterior lobe; posterior lobe somewhat swollen posterolaterally; juga more evident, more horizontal in position. Antennae $\approx 11.98$ times length of head. Ratio of antennal segment lengths $\approx 15.52: 12.57: 1.00: 7.43$.

Thorax more elongate, ratio of notal lengths to body width $\approx 1.74: 1.48: 1.20$. Pronotum more developed posterolaterally, margin touching prospiracular swelling; sternum with pair of submedial, irregular longitudinal rows of 9-18 setigerous, brown pustules. Meso- and metanotal wing pads more developed. Prothoracic legs (Fig. 15) more spinose; femora with antero- and posteroventral longitudinal rows of 12-19 and 17-25 spines, respectively; tibiae with anteroventral longitudinal row of 11-16 spines.
Abdomen with pair of discontinuous, longitudinal brown bands on terga 4-6, frequently on tergum 3 . Medial brown stripe on tergum 7 bifurcated anteriorly. Sternum 9 with midtransverse sulcus.

Fourth Instar (Fig. 7). Length, $10.51 \pm 0.16$; width, $0.58 \pm 0.01$. Body with more setigerous pustules. Head with middorsal transverse sulcus well developed; anterior lobe $\approx 1.11$ times length of posterior lobe; posterior lobe more swollen posterolaterally. Antennae $\approx 13.19$ times length of head. Ratio of antennal segment lengths $\approx 18.71: 15.71: 1.00: 7.45$.

Thorax more elongate; ratio of notal lengths to body width $\approx 2.04: 1.57: 1.35$. Pronotum more developed posterolaterally, spiracles directed ventrolaterad; sternum with pair of submedial, irregular longitudinal rows of 25-35 setigerous, brown pustules. Meso- and metanotal wing pads more developed. Mesosternum with few anterior white to yellowish white setigerous pustules. Metasternum usually with pair of posterior, submedial brown marks; posteriorly with few setiger- 
ous pustules. Prothoracic legs (Fig. 16) more spinose; femora with antero- and posteroventral longitudinal rows of 19-25 and 26-32 spines, respectively; tibiae with anteroventral longitudinal row of 16-19 spines.

Abdomen with pair of discontinuous, longitudinal brown bands present on terga 2-6. Sternum 9 noticeably constricted posterior to ventral midtransverse sulcus.

Fifth Instar (Fig. 8). Length, $15.35 \pm 0.32$; width, $0.77 \pm 0.02$. Body with more setigerous pustules. Head with anteclypeus appearing as small white to yellowish white band anterior to brown band on postclypeus; anterior lobe $\approx 1.17$ times length of posterior lobe; posterior lobe distinctly swollen. Antennae $\approx 13.36$ times length of head. Ratio of antennal segment lengths $\approx 19.84: 17.03: 1.00: 6.94$.

Thorax more elongate; ratio of notal lengths to body width $\approx 2.31: 1.71: 1.56$. Prosternum with pair of submedial, irregular longitudinal rows of 44-58 setigerous, brown pustules. Meso- and metanotal wing pads similar to those of fourth instar. Mesosternum with dense, anterior, white to yellowish white setigerous pustules. Metasternum always with pair of posterior, submedial brown marks; posteriorly with more setigerous pustules. Prothoracic legs (Fig. 17) more spinose; femora with antero- and posteroventral longitudinal rows of 24-30 and 35-39 spines, respectively, usually with small spine of variable size and length just basad of large basal spine of posteroventral series; tibiae with anteroventral longitudinal row of 17-22 spines.

Abdomen with posterior margin of sternum 8 and basal half of 9 showing developing external genitalia (Figs. 9-12). Sternum 9 more noticeably constricted posterior to midtransverse sulcus. Terminal segments further modified, showing distinct sexual dimorphism, males with posterior margin of tergum 7 slightly extended posteriorly (Fig. 11), females with tergum 8 somewhat extending posteriorly and laterally (Fig. 12).

Diagnosis. The five instars are distinguished readily by characters other than body size and ratios of various measurements. The first instar differs from the second-fifth instars by the lack of wing pads; these later instars show progressive development of wing pads up to the fourth instar, which is similar to the fifth. The third-fifth instars can be distinguished by progressive genital development, which first appears in the third instar as a midtransverse sulcus on abdominal sternum 9 and is followed by noticeable constriction of the segment posterior to the sulcus in the fourth and distinct sexual dimorphism in the fifth.

\section{Acknowledgments}

We thank the following faculty and staff members of Southern Illinois University at Carbondale: B. M. Burr and W. G. Dyer (Department of Zoology) for their critical reviews of the manuscript; J. A. Beatty (Department of Zoology) for identification of spiders; J. J. Bozzola, S. J. Schmitt, and Hilary "Dee" Gates (Integrated Microscopy and Graphics Expertise) for use of their facilities, technical expertise, and assistance in producing electron micrographs; J. R. Bray, Jr. (Department of Plant Biology) for the identification of bryophytes and Mike Mibb (Department of Plant Biology) for the identification of all other flora; T. R. Anthony (Department of Zoology) for his statistical expertise; and Beth Burke (Department of Zoology) for supplying the fruit fly cultures. We also thank D. W. Webb (Illinois Natural History Survey, Champaign); E. D. DeWalt (Illinois Natural History Survey, Champaign) and Terry L. Harrison (Department of Entomology, University of Illinois, Urbana); and R. J. Snider (Department of Zoology, Michigan State University, East Lansing) for their identifications of dipteran, lepidopteran, and collembolan prey, respectively. We also are grateful to A. M. Haggerty (Clemson University, Clemson, SC) for his discovery of P. umbrosus at Little Grand Canyon and preliminary observations on this species, and R. W. Sites (Department of Entomology, University of Missouri, Columbia) for his input on illustration techniques. Finally, we thank the U.S. Forest Service for granting permission to collect in the Shawnee National Forest, and R. L. Johnson (U.S. Forest Service, Vienna Ranger Station) for expediting processing of the permit application form. This article is part of a thesis submitted to Southern Illinois University at Carbondale by J.D.B. in partial fulfillment of the requirements for the M.S. degree in zoology.

\section{References Cited}

Blatchley, W. S. 1926. Heteroptera or true bugs of eastern North America with special reference to the faunas of Indiana and Florida. Nature Publ. Co., Indianapolis. 1116 pp.

Froeschner, R. C. 1988. Family Reduviidae Latreille, 1807. The assassin bugs, pp. 616-651. In T. J. Henry and R. C. Froeschner [eds.], Catalog of the Heteroptera, or true bugs, of Canada and the continental United States. E. J. Brill, New York. 958 pp.

Hagerty, A. M., and J. E. McPherson. 1999. Survey of the Reduviidae (Heteroptera) of southern Illinois, excluding the Phymatinae, with notes on biology. Great Lakes Entomol. 32: 133-160.

Hopkins, M. E., and J. A. Simon. 1975. Pennsylvanian system, pp. 163-201. In H. B. Willman, E. Atherton, T. C. Buschbach, C. Collinson, J. C. Frye, M. E. Hopkins, J. A. Lineback, and J. A. Simon, Handbook of Illinois stratigraphy. Illinois State Geol. Surv. Bull. 95: 1-261.

McPherson, J. E. 1991a. Noteworthy range extensions of three emesine species (Heteroptera: Reduviidae). Great Lakes Entomol. 24: 99-101.

McPherson, J. E. 1991b. Range extensions of three emesine species in North America (Heteroptera: Reduviidae). Great Lakes Entomol. 24: 263-264.

Mohlenbrock, R. H. 1977. Evaluation of Little Grand Canyon Jackson County, Illinois for eligibility of Registered Natural Landmark designation. For. Serv. public file 2360, Spec. Interest Areas, Little Grand Canyon. United States Forest Service. Murphysboro, IL. 7 pp.

Wygodzinsky, P. W. 1966. A monograph of the Emesinae (Reduviidae, Hemiptera). Bull. Am. Mus. Nat. Hist. 133: $1-614$ 